\title{
The Effect of Soluble Ammonium Polyphosphate on the Properties of Water Blown Semirigid Polyurethane Foams
}

\author{
Weiguo Yao, Hanmo Wang, Dongbo Guan, Tao Fu, Tianqi Zhang, and Yanli Dou
}

The Ministry of Education Key Laboratory of Automotive Material, College of Material Science and Engineering, Jilin University, Changchun 130025, China

Correspondence should be addressed to Yanli Dou; douyl@jlu.edu.cn

Received 17 November 2016; Revised 21 February 2017; Accepted 2 March 2017; Published 20 April 2017

Academic Editor: Hongchao Kou

Copyright (c) 2017 Weiguo Yao et al. This is an open access article distributed under the Creative Commons Attribution License, which permits unrestricted use, distribution, and reproduction in any medium, provided the original work is properly cited.

Soluble ammonium polyphosphate (SAPP) is employed to prepare flame retardant semirigid polyurethane foam (SPUF) using water as blowing agent. The flame retardant property of SPUF is evaluated by limiting oxygen index (LOI) and horizontal burning test. Also the thermal degradation mechanism is studied by TG and Fourier transform infrared (FTIR). The results show that, with the increase of the content of SAPP, flame retardant property of SPUF improves obviously as the LOI value increases and the horizontal burning rate decreases. And residual char is increased up to $20 \%$ with $19 \mathrm{wt} \%$ SAPP. Moreover, the mechanical property of SPUF is enhanced dramatically.

\section{Introduction}

Polyurethane foam is regarded as a versatile polymeric material for its comparatively excellent properties such as low density, high specific strength, great insulation, large specific surface area, and good sound-absorbing performance. Polyurethane foam is more easily burned compared to other foams since there are many easily decomposing urea bonds in it [1]. Thus, it is necessary to improve the flame retardant property of polyurethane foam $[2,3]$.

By now the flammability of flexible polyurethane foams (FPUF) is studied widely [4-6]. Matthias et al. investigated the phosphoramidate-containing flame retardant systems for FPUF. Chen et al. worked on the mechanism of halogenfree retardant agent on FPUF. A. König studied the effect of the new flame retardant methyl-DOPO properties on FPUF. Also, the flame retardant property of rigid polyurethane foams (RPUF) was studied widely [7-12]. In these years, however, semirigid polyurethane foam (SPUF) is generally used in various fields, such as leather processing, textile printing, paper-making industry, architectural coatings, adhesives, and cushioning materials. Some flame retardants, EG, halogencontaining flame retardant, and phosphate ester were added to SPUF to improve the fire resistance [13-16].
Ammonium polyphosphate (APP), as inorganic phosphorus flame retardant with nitrogen-phosphorus synergistic intumescent effect [17-20], has the advantages of thermal stability and lasting effect. APP can also improve the mechanical properties of the material, so it is often used with other flame retardants [21-23], and the most common APP flame retardant studied by researchers is form II, of which the polymerization degree is greater than 1000 [24-27]. In this paper, the water blown SPUF is synthesized only with soluble ammonium polyphosphate (SAPP) with a low polymerization degree. Our aim is to study the effect of SAPP on the thermal degradation, the flame-resistant, and the mechanical properties of the SPUF.

\section{Experimental}

2.1. Materials. The main materials were as follows: polyester polyols (330N/3630, Yiju-Polymer Materials Co., Ltd.), isocyanate (MDI, Yiju-Polymer Materials Co., Ltd.), triethanolamine (AR/Beijing Chemical Factory), silicone oil (8681, Yiju-Polymer Materials Co., Ltd.), stannous octoate (Yiju-Polymer Materials Co., Ltd.), and water-soluble ammonium polyphosphate form I (the molecular weight of SAPP is 1649 g/mol, Zhenjiang Star Flame retardant Co., Ltd.). 
TABLE 1: Burning test results with different content APP for SPUF.

\begin{tabular}{lcccc}
\hline Samples & APP wt/\% & LOI/\% & $\begin{array}{c}\text { Horizontal burning rate } \\
(\mathrm{mm} / \mathrm{min}) / \text { self-extinguished time (s) }\end{array}$ & UL-94 \\
\hline SPUF & 0 & 18.9 & 49.01 & 36.61 \\
SPUF/APP5 & 5 & 22.2 & $172.81 \mathrm{SET}$ & HBF \\
SPUF/APP7 & 7 & 22.4 & $69.66 \mathrm{SET}$ & HBF \\
SPUF/APP $_{9}$ & 9 & 22.7 & $34.52 \mathrm{SET}$ & HBF \\
SPUF/APP $_{11}$ & 11 & 22.8 & $31.52 \mathrm{SET}$ & HBF \\
SPUF/APP $_{13}$ & 13 & 22.9 & 29.94 SET & HBF \\
SPUF/APP $_{15}$ & 15 & 23.2 & 28.59 SET & HF-1 \\
SPUF/APP $_{17}$ & 17 & 24.1 & 27.25 SET & HF-1 \\
SPUF/APP $_{19}$ & 19 & 24.5 & HF-1 \\
\hline
\end{tabular}

2.2. Water Blown Polyurethane Foams Preparation. In order to explore the effect of SAPP content on the flame retardant properties of PU, in this experiment, different content SAPP ( $5 \mathrm{wt} \%, 7 \mathrm{wt} \%, 9 \mathrm{wt} \%, 11 \mathrm{wt} \%, 13 \mathrm{wt} \%, 15 \mathrm{wt} \%, 17 \mathrm{wt} \%$, and $19 \mathrm{wt} \%)$ was added to the $100 \mathrm{~mL}$ plastic cup, respectively, with polyester polyols $330 \mathrm{~N}, 3630$, triethanolamine, silicone oil, distilled water, triethylenediamine, and stannous octoate. The mixture of monomers and additive was first stirred using an electric stirrer for 60 seconds until a uniform liquid was obtained. Then, MDI was added to the mixture, reacting with distilled water to inflate the reactants. About 3 5 minutes later, transfer the mixture into a foaming box $(L \times B \times H=$ $15 \times 15 \times 6 \mathrm{~cm}^{3}$ ) completely and quickly for further frothy bubbles forming. Finally, the foam was put into an oven heating for 24 hours at $50^{\circ} \mathrm{C}$ and the sample for measurement was prepared.

\subsection{Characterization}

2.3.1. LOI Test. LOI (standard test method for measuring the minimum oxygen concentration to support candle-like combustion of plastics) was measured with an JF-3 oxygen index test instrument (made in Nanjing Analytical Instruments Company, China) on sheets of size $100 \mathrm{~mm} \times 10 \mathrm{~mm} \times$ $10 \mathrm{~mm}$ according to the standard "oxygen index" test ASTMD 2863-97.

2.3.2. Horizontal Burning Test. Horizontal burning tests were performed with a H1011D horizontal burning instrument (Changchun, China) on sheets of size $130 \mathrm{~mm} \times 70 \mathrm{~mm} \times$ $10 \mathrm{~mm}$ according to the standard horizontal burning test ASTMD 635-98, the wind speed is $0.3 \mathrm{~m} / \mathrm{s}$ in the experiment, and the combustion property of foams was referred to the UL94 test standards.

2.3.3. Thermogravimetric Analyses (TG). TG were carried out at $10^{\circ} \mathrm{C} / \mathrm{min}$ under nitrogen flow (flow rate: $40 \mathrm{~mL} / \mathrm{min}$ ) with a NETZSCH STA 449F3 (Germany) thermogravimetric analyzer. In each case, the mass of the sample powder was 2 to $5 \mathrm{mg}$, and the samples were heated from $25^{\circ} \mathrm{C}$ to $800^{\circ} \mathrm{C}$ at the rate of $10^{\circ} \mathrm{C}$ per min.
2.3.4. Fourier Transform Infrared. Fourier transform infrared (FTIR) spectra were obtained by TENSOR 27 FTIR spectrometer (Germany Bruker) in the range of $600-4000 \mathrm{~cm}^{-1}$ with transmission infrared ray test.

2.3.5. Scanning Electron Microscopy (SEM). Scanning electron microscopy (SEM) was performed with a ZEISS EVO18 (Carl Zeiss, Germany) SEM with an accelerating voltage of $20 \mathrm{kV}$. The samples were obtained by impacting into fractures at a room temperature, including original and burned samples.

\subsubsection{Mechanical Properties Test}

Shaw Hardness Test. The experiment was carried out according to the polyurethane foam hardness test standards of the soft automotive instrument panel. The foams with PVC skins were measured on the Shore scleroscope hardness. Ten points were chosen to be measured for each sample and got the average values finally.

Compression Test. Compression test was carried out with a WSM-5KN universal testing machine (Changchun, China) on sheets of size $50 \mathrm{~mm} \times 50 \mathrm{~mm} \times 50 \mathrm{~mm}$ according to the standard GB8813-88. The rate of compression was $10 \mathrm{~mm} / \mathrm{min}$.

Density Test. Apparent density of samples was calculated according to GB/T6343-1995. The sizes of the specimens were $50 \mathrm{~mm} \times 50 \mathrm{~mm} \times 50 \mathrm{~mm}$. Test six specimens and then get the average values.

\section{Results and Discussion}

3.1. Flame-Resistant Properties. LOI and horizontal burning rate are important indicators of material's flame-resistant properties. The burning test results for water blown SPUF with different content of flame retardant APP are presented in Table 1.

As shown in Table 1, the LOI value increases and horizontal burning rate decreases with the increasing of APP. 


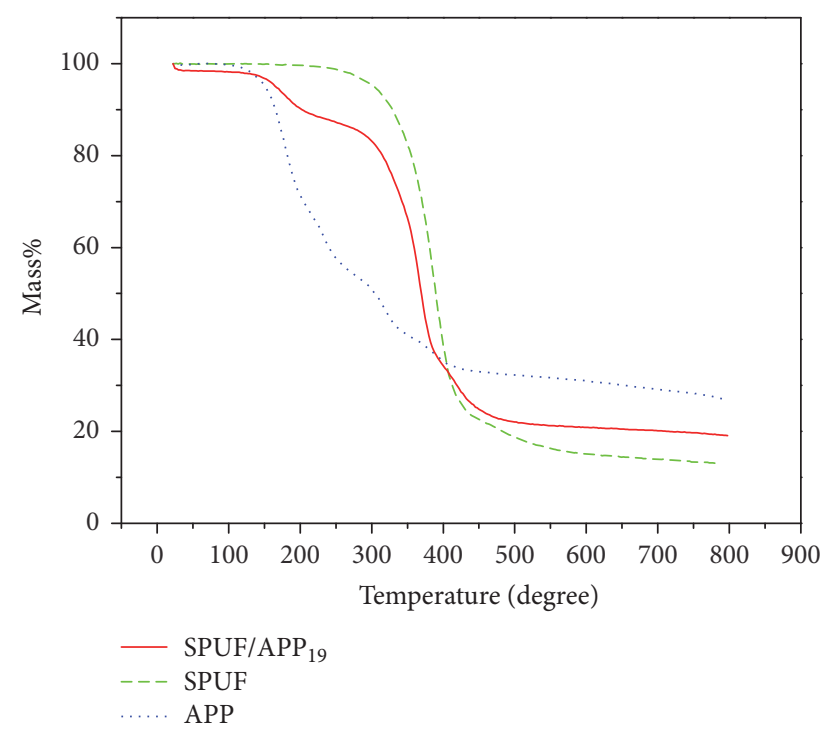

(a)

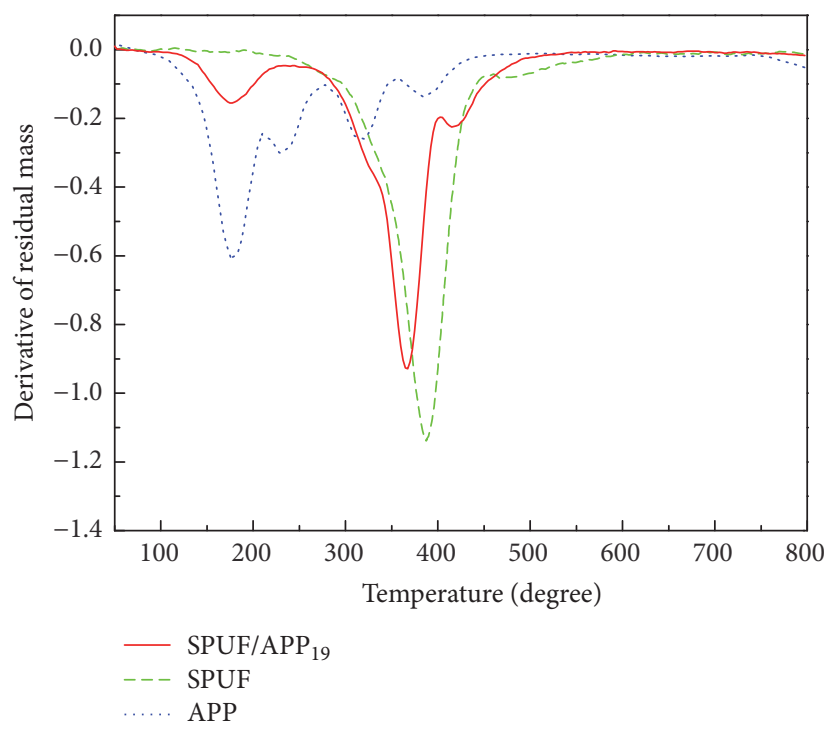

(b)

FIGURE 1: TG and DTG curves of samples.

TABLE 2: Details of TG and DTG curves.

\begin{tabular}{|c|c|c|c|c|}
\hline Samples & Initial decomposition temperature $\left({ }^{\circ} \mathrm{C}\right)$ & Temperature of stages $\left({ }^{\circ} \mathrm{C}\right)$ & $T_{\max }\left({ }^{\circ} \mathrm{C}\right)$ & Residual char (\%) \\
\hline \multirow{3}{*}{ SPUF/APP $_{19}$} & \multirow{3}{*}{ 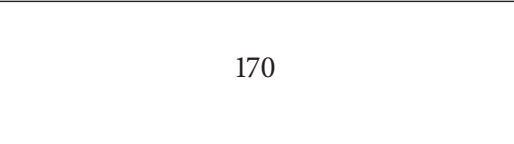 } & (1) $100 \sim 225$ & (1) 190 & \multirow{3}{*}{20} \\
\hline & & (2) $225 \sim 390$ & (2) 355 & \\
\hline & & (3) $390 \sim 500$ & (3) 410 & \\
\hline \multirow{2}{*}{ SPUF } & \multirow{2}{*}{300} & (1) $200 \sim 450$ & (1) 390 & \multirow{2}{*}{15} \\
\hline & & (2) $450 \sim 600$ & (2) 490 & \\
\hline \multirow{4}{*}{ APP } & \multirow{4}{*}{180} & (1) $100 \sim 225$ & (1) 180 & \multirow{4}{*}{25} \\
\hline & & (2) $225 \sim 275$ & (2) 250 & \\
\hline & & (3) $275 \sim 360$ & (3) 325 & \\
\hline & & (4) $360 \sim 440$ & (4) 390 & \\
\hline
\end{tabular}

According to the results of horizontal burning tests, the pure SPUF does not show self-extinguishing until the content of APP reaches up to $7 \mathrm{wt} \%$. SPUF/APP ${ }_{15 \sim 19}$ achieves UL-94-HF-1 rating and the highest LOI reaches $24.5 \%$ in SPUF/APP 19 . These results illustrate that SAPP improves the flame retardant properties of SPUF effectively. However, the addition of SAPP will constantly increase the viscosity of the reaction system and extend the period of foaming time dramatically. So the content of SAPP should be no more than $19 \%$.

A serious dropping phenomenon was observed during the burning process of SPUF. It produced a combustible flow of tar. And the dropping phenomenon had appeared before the polymer formed a charred layer. APP as an effective intumescent fire retardant with the synergistic effect of nitrogen-phosphorus plays the role of acid and gas source in the process of foam combustion [18], promoting the formation of porous carbonaceous chars and preventing the droplets formation. The flame retardant mechanism can be explained where the thermal decomposition products of APP, ammonia, and water act as a physical barrier diluting the concentration of combustible gases and oxygen to exert a flame retardant effect [20].

3.2. Thermogravimetric Analysis. Figure 1 shows TG and DTG curves of SPUF/APP ${ }_{19}$, pure water blown SPUF, and APP. APP has four stages, the exact temperature ranges of these stages are as shown in Table 2. The first stage is corresponding to the release of ammonia, carbon dioxide, and polyphosphoric acid. The second occurs around 235 $275^{\circ} \mathrm{C}$ in which the weight loss rate is up to $40 \%$, and the third stage is approximately within $275 \sim 360^{\circ} \mathrm{C}$; both of them are caused by the dehydration and continual cross-link reaction of polyphosphoric acid. The last stage within $360 \sim 440^{\circ} \mathrm{C}$ is caused by the cross-linked structure of polyphosphoric acid and thermal decomposition of other residual products. The residual char of APP is about 25\%. There are two thermal decomposition stages of SPUF, corresponding to the decomposition of amino formic acid ester at the C-O bond and polyol, respectively [28]. Temperature of maximal weight 


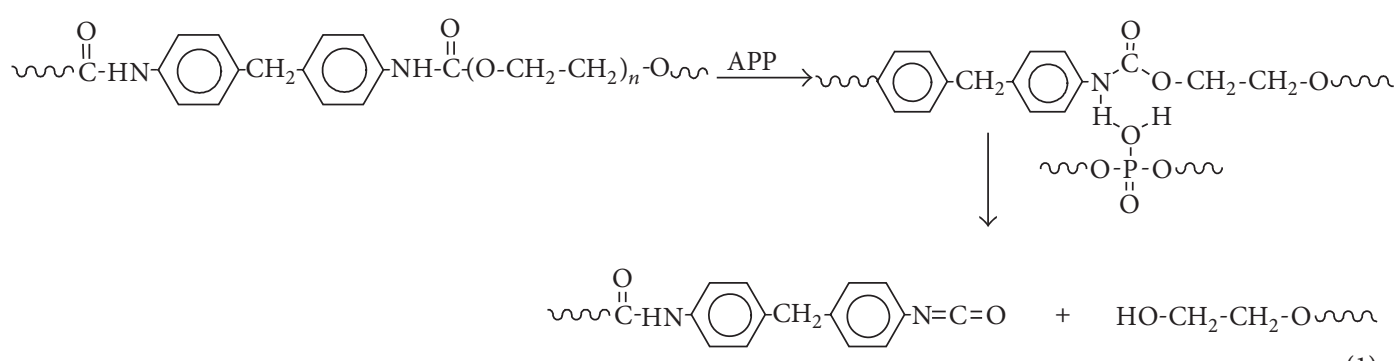

FIGURE 2: The catalytic reaction of APP and PU.

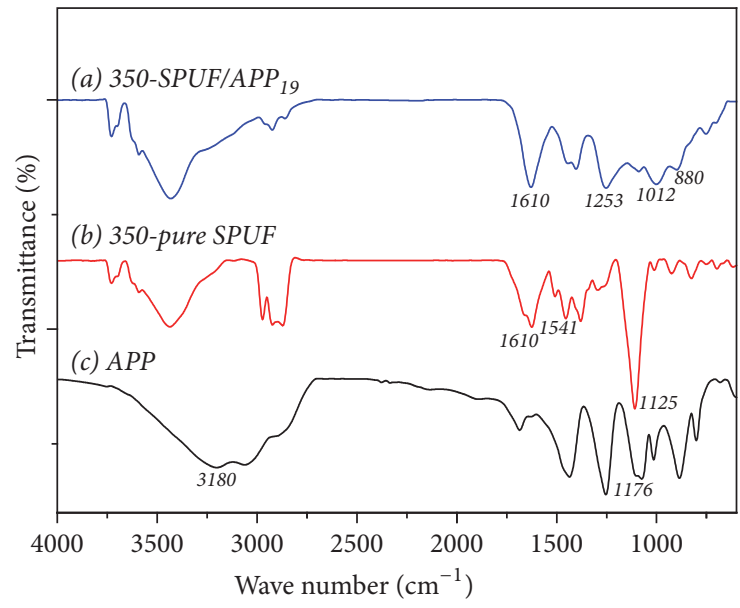

FIGURE 3: FTIR of pure SPUF, SPUF/APP ${ }_{19}$, and APP.

loss rate $\left(T_{\max }\right)$ is at $370^{\circ} \mathrm{C}$ roughly, and residual char is $15 \%$ at $800^{\circ} \mathrm{C}$. Compared to SPUF, the initial decomposition temperature $\left(T_{\text {in }}\right)$ and $T_{\max }$ of SPUF/APP ${ }_{19}$ decrease, resulting from the fact that phosphoric acid catalyzes the degradation of ammonia ester bond [29, 30]. The catalytic reaction between APP and PU is shown as (1) in Figure 2. The residual char is increased to $20 \%$. It illustrates that APP can promote the formation of residual char. The char layer is nonflammable, which plays a role of good insulation and prevents the oxygen from entering the underlying unburnt material, and inhibits the combustion to some degree. The flame retardant property of water blown SPUF improved remarkably with the increase of the mass of residual char $[1,23]$.

3.3. Fourier Transform Infrared. FTIR spectra of pure SPUF and SPUF/APP 19 calcined at $350^{\circ} \mathrm{C}$, APP at room temperature, are shown in Figure 3. The (c) spectrum shows the typical characteristic peaks of 1176 and $3180 \mathrm{~cm}^{-1}$ assigned to $\mathrm{N}-\mathrm{O}$ and $\mathrm{N}-\mathrm{H}$ bonds of APP. By comparison, the (a) $350-$ SPUF/APP 19 spectrum does not show the N-O and N$\mathrm{H}$ bonds and three new characteristic peaks 1253, 1012, and $880 \mathrm{~cm}^{-1}$ assigned to $\mathrm{P}=\mathrm{O}$ symmetric stretching vibration peak, P-O symmetric stretching vibration peak, and $\mathrm{P}-\mathrm{O}$ asymmetric stretching vibration peak appear. It shows that APP has degraded at $350^{\circ} \mathrm{C}$ producing phosphoric acid and other products. By analyzing (b) 350-pure SPUF and (a) 350-SPUF/APP 19 , it can be seen that (b) spectrum shows the characteristic peaks 1541 and $1125 \mathrm{~cm}^{-1}$ of polyurethane; however, (a) spectrum only has the $1610 \mathrm{~cm}^{-1}$ stretching vibration peak of aromatic ring $\mathrm{C}=\mathrm{C}$; it concludes that 350 pure SPUF does not degrade while $350-\mathrm{SPUF} / \mathrm{APP}_{19}$ appears with the thermal decomposition due to the catalysis of APP pyrolysis product such as phosphoric acid. The analysis in this section also confirms the results of TG.

3.4. The Morphology of Charred Layer. Figures 4 and 5 show the digital pictures and SEM images of SPUF/APP 19 and SPUF after LOI test. The residual char structure of SPUF shrinks more severely and there is more foam uncovered by char, as shown by the red circle in Figure 4. As a result, the interphase is burned more severely for pure SPUF. It is also observed from SEM images that the residual char structure of SPUF sticks together, while the SPUF/APP ${ }_{19}$ remains at the original state basically.

3.5. The Morphology of Bubble Hole. Figure 6 shows the SEM micrographs of SPUF/APP 19 and SPUF. As for SPUF, the size of bubble holes is uniform, cell-walls are smooth, and there are few ruptures. As for the SPUF/APP ${ }_{19}$, SAPP is in a compatible state with the foam system, serving as the bubble nucleuses [17]; thus, the number of bubble holes increases and the size of bubble holes reduces. With generation and growing of the bubble holes, APP scatters inside the cell-walls and turns into the support structure as shown in Figure 6.

3.6. Mechanical Properties. Water blown SPUF contains both closed and open cells. The apparent density can reflect cellular structure in some degree. Table 3 illustrates that the apparent density of SPUF/APP increases when $\mathrm{W}_{\mathrm{APP}}$ is more than $11 \%$. The Shaw hardness increases with increasing of APP. The compression strength and modulus of compression improve slightly compared with SPUF, when $\mathrm{W}_{\mathrm{APP}}$ is more than $15 \%$; both of them increase significantly. It can be explained that APP acts as the bubble nucleus; a small part scatters onto the cell-walls, resulting in a growing number of bubble holes and reducing size of bubble holes. When $\mathrm{W}_{\mathrm{APP}}$ is more than $15 \%$, the filling effect of APP dominates the interaction, and APP acts as the receptor of the external load, resulting in the enhancing of the compression strength dramatically. 

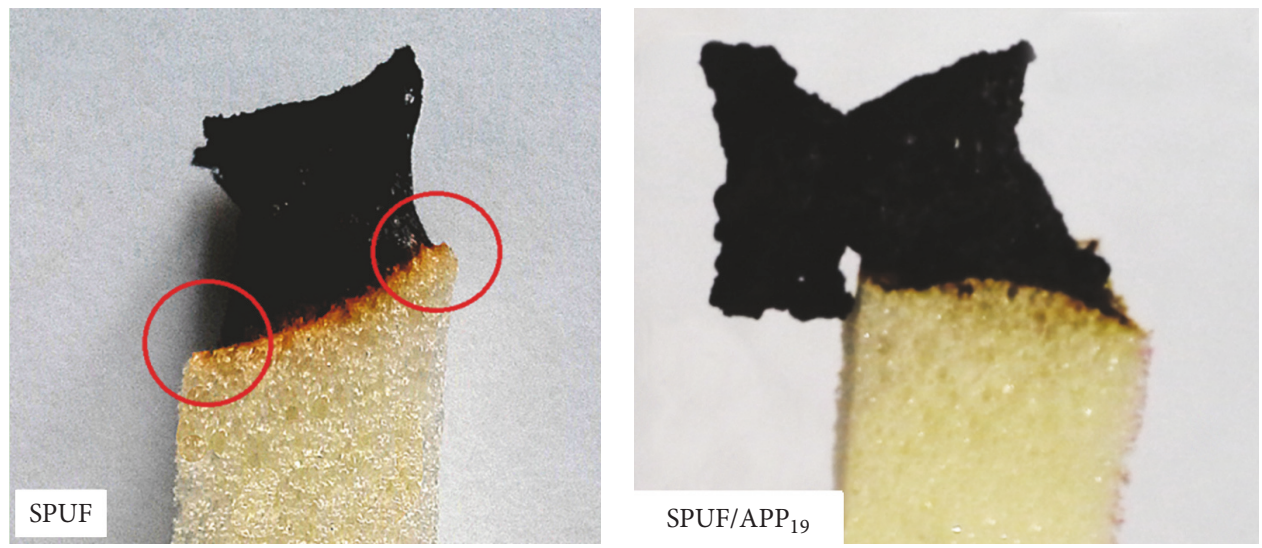

FIGURE 4: Digital photos of residual char.
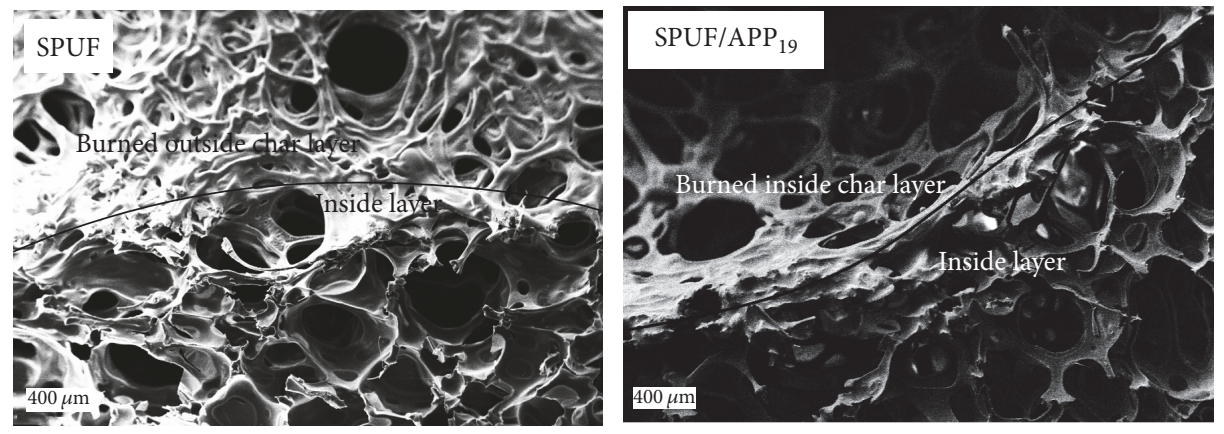

FIGURE 5: SEM images of residual char.
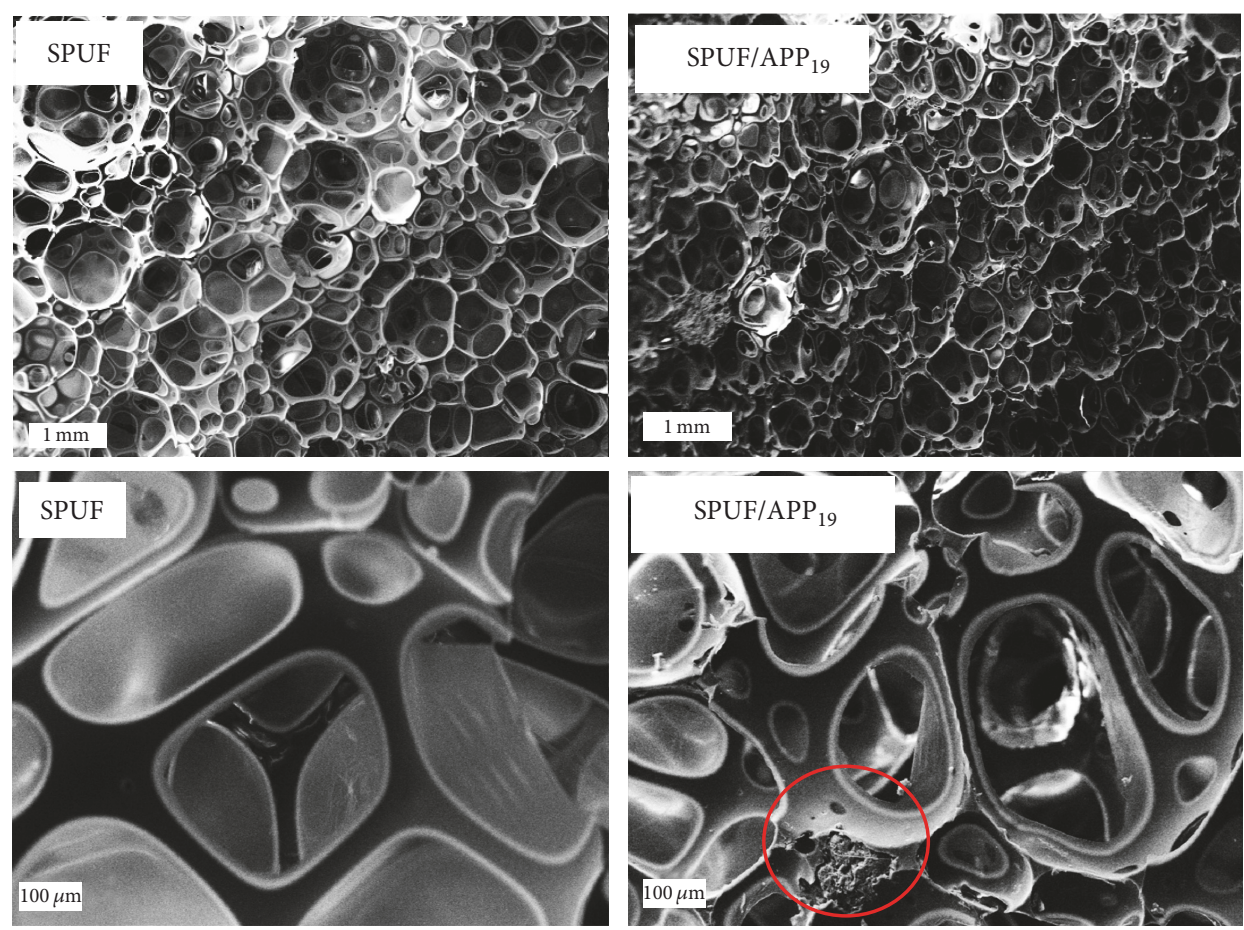

FIGURE 6: The SEM micrographs of SPUF and SPUF/APP . $_{19}$ 
TABLE 3: Influence of APP on the density, hardness, and compression performance of SPUF.

\begin{tabular}{|c|c|c|c|c|}
\hline Samples & Density $\mathrm{kg} / \mathrm{m}^{3}$ & Shaw hardness/HA & Compression strength/Mpa & Modulus of compression/Mpa \\
\hline SPUF & 46.64 & 55.64 & 0.0280 & 0.11 \\
\hline $\mathrm{SPUF} / \mathrm{APP}_{5}$ & 46.80 & 57.69 & 0.0415 & 0.50 \\
\hline $\mathrm{SPUF} / \mathrm{APP}_{7}$ & 46.36 & 57.73 & 0.0420 & 0.55 \\
\hline SPUF/APP ${ }_{9}$ & 46.45 & 57.85 & 0.0410 & 0.45 \\
\hline SPUF/APP ${ }_{11}$ & 46.00 & 58.69 & 0.0400 & 0.45 \\
\hline $\mathrm{SPUF} \mathrm{APP}_{13}$ & 52.48 & 59.46 & 0.0430 & 0.45 \\
\hline SPUF/APP $_{15}$ & 53.28 & 62.46 & 0.0445 & 0.85 \\
\hline $\mathrm{SPUF} \mathrm{APP}_{17}$ & 54.64 & 63.27 & 0.0555 & 1.00 \\
\hline SPUF/APP $_{19}$ & 61.56 & 64.77 & 0.0635 & 1.25 \\
\hline
\end{tabular}

\section{Conclusions}

The flame-retardant of SPUF is enhanced by soluble ammonium polyphosphate with low molecular weight. The SPUF becomes self-extinguished as the content of APP is higher than 7 wt $\%$. SPUF/APP $15 \sim 19$ achieves UL-94-HF-1 rating. The highest LOI reaches $24.5 \%$ when the content of APP is $19 \mathrm{wt} \%$. The decomposition temperature of SPUF decreases by the catalytic reaction between phosphoric acid of APP and imino group of PU, while the residual char reaches up to $20 \%$.

The physic-mechanical properties analysis shows that a few agglomerate particles of APP have certain damaging influence on morphology of bubble holes. The apparent density of SPUF/APP ${ }_{5-11}$ remains unchanged first, and then a gradual uptrend appears when $\mathrm{W}_{\mathrm{APP}}$ is more than $11 \%$. The Shaw hardness presents an increasing trend with the addition of APP. Both the compression strength and modulus of compression present an increasing variation with the addition of APP compared to SPUF, when $\mathrm{W}_{\mathrm{APP}}$ is more than $15 \%$; both of them increase significantly.

\section{Conflicts of Interest}

The authors declare that they have no conflicts of interest.

\section{Acknowledgments}

The authors gratefully acknowledge the Science and Technology Development Project of Jilin Province, China (no. 20150301002G X and no. 15SS15).

\section{References}

[1] C.-Q. Wang, H.-N. Lv, J. Sun, and Z.-S. Cai, "Flame retardant and thermal decomposition properties of flexible polyurethane foams filled with several halogen-free flame retardants," Polymer Engineering and Science, vol. 54, no. 11, pp. 2497-2507, 2014.

[2] K.-J. Yuan, Z. Jiang, S.-F. Li, and Y.-J. Zhou, "The fire retardant mechanism of polyurethane," Polymeric Materials Science and Engineering, vol. 22, no. 5, pp. 1-4, 2006.

[3] Y.-J. Chung, Y. Kim, and S. Kim, "Flame retardant properties of polyurethane produced by the addition of phosphorous containing polyurethane oligomers (II)," Journal of Industrial and Engineering Chemistry, vol. 15, no. 6, pp. 888-893, 2009.
[4] A. König and E. Kroke, "Methyl-DOPO—a new flame retardant for flexible polyurethane foam," Polymers for Advanced Technologies, vol. 22, no. 1, pp. 5-13, 2011.

[5] M. Neisius, S. Y. Liang, H. Mispreuve, and S. Gaan, "Phosphoramidate-containing flame-retardant flexible polyurethane foams," Industrial and Engineering Chemistry Research, vol. 52, no. 29, pp. 9752-9762, 2013.

[6] M.-J. Chen, Z.-B. Shao, X.-L. Wang, L. Chen, and Y.-Z. Wang, "Halogen-free flame-retardant flexible polyurethane foam with a novel nitrogen-phosphorus flame retardant," Industrial and Engineering Chemistry Research, vol. 51, no. 29, pp. 9769-9776, 2012.

[7] D.-H. Wu, P.-H. Zhao, Y.-Q. Liu, X.-Y. Liu, and X.-F. Wang, "Halogen Free flame retardant rigid polyurethane foam with a novel phosphorus-nitrogen intumescent flame retardant," Journal of Applied Polymer Science, vol. 131, no. 11, 2014.

[8] I. Tsuyumoto, Y. Onoda, F. Hashizume, and E. Kinpara, "Flameretardant rigid polyurethane foams prepared with amorphous sodium polyborate," Journal of Applied Polymer Science, vol. 122, no. 3, pp. 1707-1711, 2011.

[9] M. Thirumal, N. K. Singha, D. Khastgir, B. S. Manjunath, and Y. P. Naik, "Halogen-free flame-retardant rigid polyurethane foams: effect of alumina trihydrate and triphenylphosphate on the properties of polyurethane foams," Journal of Applied Polymer Science, vol. 116, no. 4, pp. 2260-2268, 2010.

[10] M. Li, J. Luo, Y. Huang, X. Li, T. Yu, and M. Ge, "Recycling of waste poly(ethylene terephthalate) into flame-retardant rigid polyurethane foams," Journal of Applied Polymer Science, vol. 131, no. 19, Article ID 40857, 2014.

[11] J. Paciorek-Sadowska, B. Czuprynski, and J. Liszkowska, "Glycolysis of rigid polyurethane-polyisocyanurate foams with reduced flammability," Journal of Elastomers and Plastics, vol. 48, no. 4, pp. 340-353, 2016.

[12] W. Xing, H. Yuan, P. Zhang, H. Yang, L. Song, and Y. Hu, "Functionalized lignin for halogen-free flame retardant rigid polyurethane foam: preparation, thermal stability, fire performance and mechanical properties," Journal of Polymer Research, vol. 20, no. 9, article 234, 2013.

[13] C. R. Tian, Q. M. Zhou, X. P. Liu, and J. H. Wang, "Preparation of flame retardant semi-rigid integral-skin polyurethane foam," Plastics Science and Technology, vol. 31, no. 1, pp. 24-27, 2003.

[14] Y. Li, J. Zou, S. T. Zhou et al., "Effect of expandable graphite particle size on the flame retardant, mechanical, and thermal 
properties of water-blown semi-rigid polyurethane foam," Journal of Applied Polymer Science, vol. 131, no. 3, Article ID 39885, 2014.

[15] J. Zou, Y. Chen, M. Liang, and H. Zou, "Effect of hard segments on the thermal and mechanical properties of water blown semirigid polyurethane foams," Journal of Polymer Research, vol. 22, no. 6 , article 120, 2015.

[16] W. L. Li, L. Z. Liu, X. R. Zhang, L. Weng, and W. W. Cui, "Effect of expandable graphite on properties of semi-rigid polyurethane foam," Engineering Plastics Application, vol. 43, no. 8, pp. 1-5, 2015.

[17] H. Yan, X. X. Du, J. K. Zhang, L. Q. Wei, and B. S. Xu, "Property of polypropylene with addition of ammonium polyphosphate flame retardant," Journal of Taiyuan University of Technology, vol. 45, no. 4, pp. 431-436, 2014.

[18] Q. W. Sun and F. Y. Lu, "Environment friendly APP flame retardant has an attractive prospect," Science-Technical on MiddleSmall Business, no. 4, article 16, 2005.

[19] Q. W. Sun, "Enviroment friendly APP flame retardant has an attractive prospect," Henan Chemical Industry, vol. 21, no. 3, 2004.

[20] Y. L. Liu, J. Y. He, and R. J. Yang, "The effects of aluminum hydroxide and ammonium polyphosphate on the flame retardancy and mechanical property of polyisocyanurate-polyurethane foams," Journal of Fire Sciences, vol. 33, no. 6, pp. 459472, 2015.

[21] X.-Y. Meng, L. Ye, X.-G. Zhang et al., "Effects of expandable graphite and ammonium polyphosphate on the flame-retardant and mechanical properties of rigid polyurethane foams," Journal of Applied Polymer Science, vol. 114, no. 2, pp. 853-863, 2009.

[22] G. S. Tay, L. N. Ong, and H. D. Rozman, "Mechanical properties and fire retardant behavior of polyurethane foam reinforced with oil palm empty fruit bunch," Journal of Applied Polymer Science, vol. 125, no. 1, pp. 158-164, 2012.

[23] Q. Zhang, J. Liu, L. J. Sun, J. L. Bai, and X. M. Sang, "Effect of APP on cell structure and mechanical properties of rigid polyurethane-imide foams," Plastics, vol. 44, no. 5, pp. 7-10, 2015.

[24] F. Luo, K. Wu, Y. Li, J. Zheng, H. Guo, and M. Lu, "Reactive flame retardant with core-shell structure and its flame retardancy in rigid polyurethane foam," Journal of Applied Polymer Science, vol. 132, no. 46, Article ID 42800, 2015.

[25] F. Luo, K. Wu, H. Guo, Q. Zhao, L. Liang, and M. Lu, "Effect of cellulose whisker and ammonium polyphosphate on thermal properties and flammability performance of rigid polyurethane foam," Journal of Thermal Analysis and Calorimetry, vol. 122, no. 2, pp. 717-723, 2015.

[26] B. Wang, S. Hu, K. Zhao, H. Lu, L. Song, and Y. Hu, "Preparation of polyurethane microencapsulated expandable graphite, and its application in ethylene vinyl acetate copolymer containing silica-gel microencapsulated ammonium polyphosphate," Industrial \& Engineering Chemistry Research, vol. 50, no. 20, pp. 11476-11484, 2011.

[27] F. Luo, K. Wu, and M. Lu, "Enhanced thermal stability and flame retardancy of polyurethane foam composites with polybenzoxazine modified ammonium polyphosphates," RSC Advances, vol. 6, no. 16, pp. 13418-13425, 2016.

[28] F. Long, S. Q. Hu, Q. P. Wei, and X. Wang, "Pyrolysis characteristics and kinetics of flexible polyurethane foam before smoldering," Journal of Nanjing Tech University, vol. 36, no. 5, pp. 112-117, 2014.
[29] S. Duquesne, M. Le Bras, S. Bourbigot et al., "Mechanism of fire retardancy of polyurethanes using ammonium polyphosphate," Journal of Applied Polymer Science, vol. 82, no. 13, pp. 3262-3274, 2001.

[30] N. Grassie, M. Zulfiqar, and G. Scott, Developments in Polymer Stabilisation, vol. 1, Applied Science Publishers, 1978. 

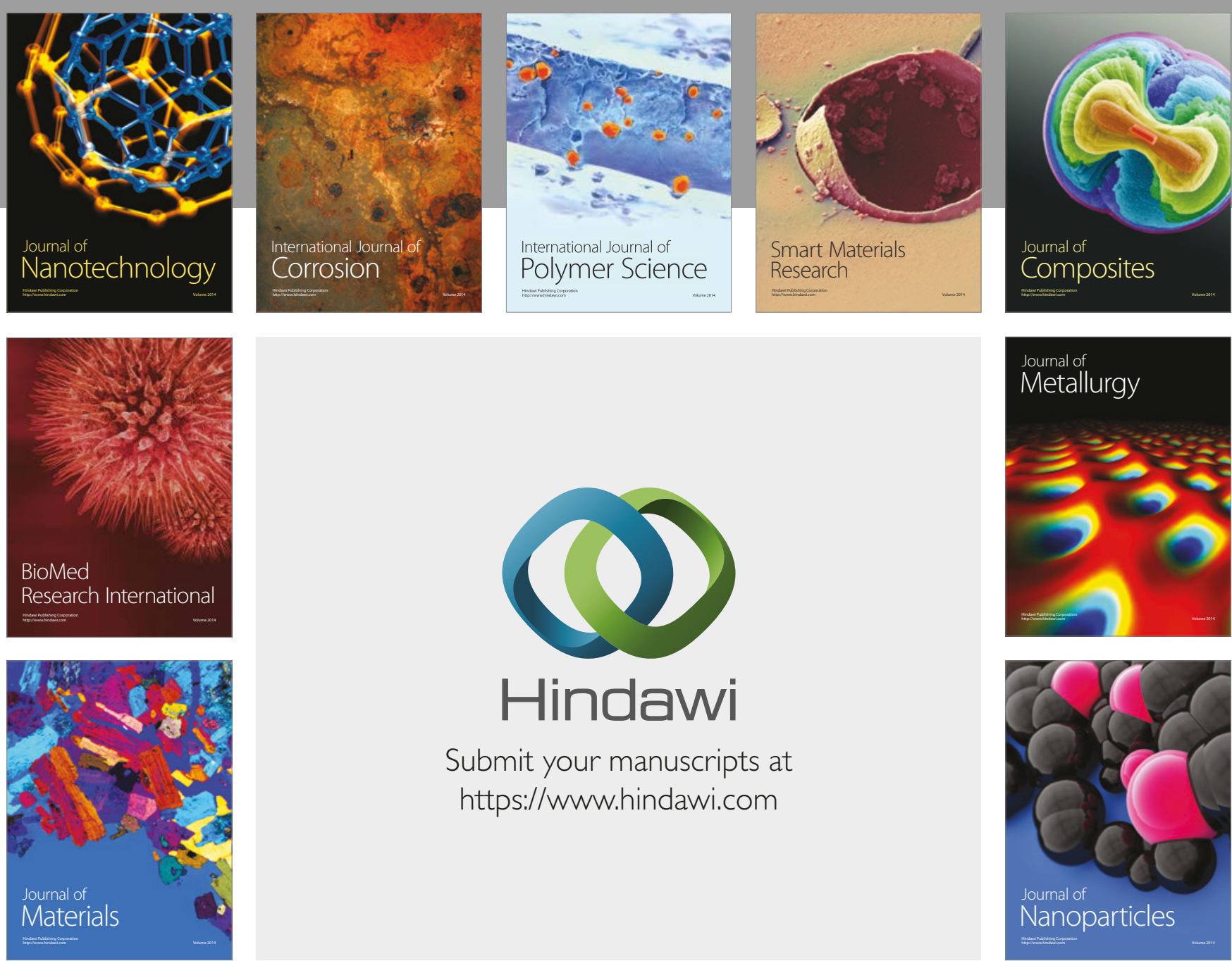

\section{Hindawi}

Submit your manuscripts at

https://www.hindawi.com
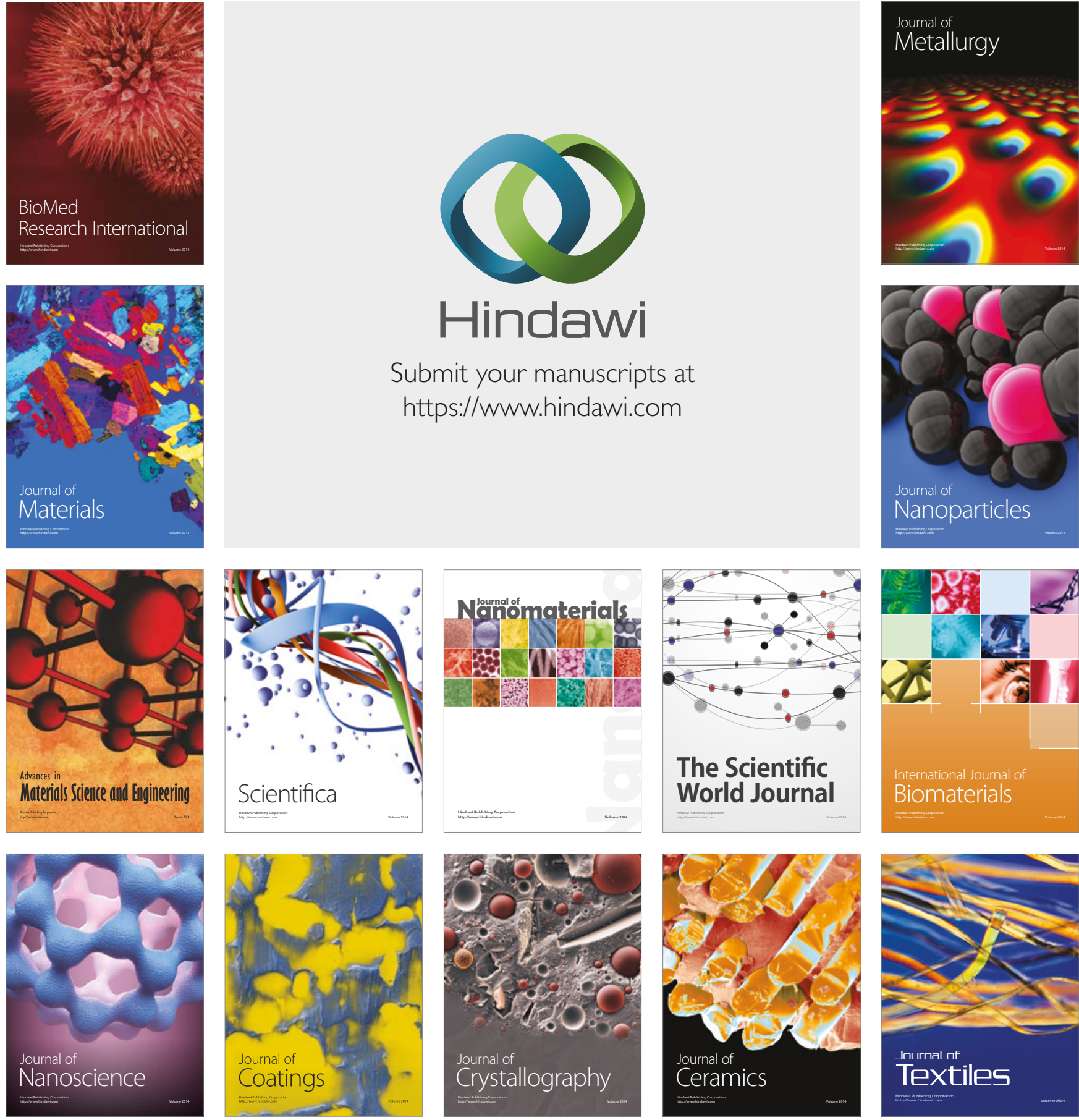

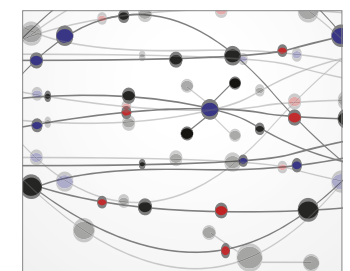

The Scientific World Journal
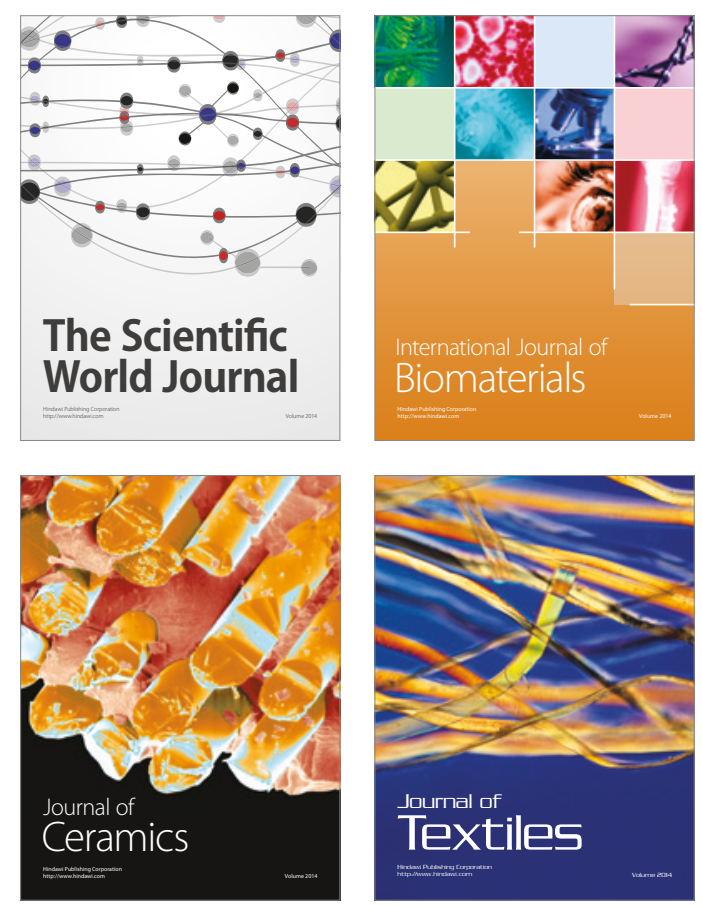